\title{
Employment Opportunities and Population Agglomeration: A Study Based on a Sub-Industry Perspective
}

\author{
Xiujuan Xiao \\ College of Economics, Jinan University, Guangzhou, China \\ Email: 13535539629@163.com
}

How to cite this paper: Xiao, X. J. (2020). Employment Opportunities and Population Agglomeration: A Study Based on a SubIndustry Perspective. Open Journal of Social Sciences, 8, 113-121.

https://doi.org/10.4236/jss.2020.83011

Received: February 10, 2020

Accepted: March 8, 2020

Published: March 11, 2020

Copyright () 2020 by author(s) and Scientific Research Publishing Inc. This work is licensed under the Creative Commons Attribution International License (CC BY 4.0).

http://creativecommons.org/licenses/by/4.0/

\section{(c) (i) Open Access}

\begin{abstract}
This paper uses the data of prefecture-level and above cities to establish a model to study the impact of employment opportunities on population agglomeration. It is found as follows: First, on the whole, employment opportunities have a significant impact on population agglomeration. Sub-industry, industrial and modern services Employment have a significant positive impact on population agglomeration, and the impact of employment in traditional services is not significant. Secondly, the impact of employment on population agglomeration is decreasing after 2012. The impact of industrial employment on population agglomeration has become insignificant. The impact of modern service industry employment on population agglomeration is still significant, but its influence is gradually decreasing. Finally, from other variables, the initial population density, infrastructure level and medical level are positively correlated with population agglomeration, and the level of economic development is negatively correlated with population agglomeration.
\end{abstract}

\section{Keywords}

Population Agglomeration, Employment Opportunities, Industry, Traditional Services, Modern Services

\section{Introduction}

Population agglomeration can not only bring abundant human capital to the agglomerated areas, but also provide a human guarantee for the economic development of the agglomerated areas. China is currently in a rapid urbanization stage, the urbanization rate of the resident population nationwide was $58.52 \%$ in 2017, which was 1.17 percentage points higher than the previous year. The 
prefecture-level cities play an important role in the process of urbanization in China. In 2016, the proportion of permanent residents in prefecture-level cities and above accounted for $60.17 \%$ of the total urban population. Although the overall size of China's urban population is rising, China's urbanization level is still low and the population concentration is not high. According to the research by Su \& Wei (2013), the optimal urban population density in China is 13,000 people per square kilometer, but the population density of cities at and above the prefecture-level was only 8800 people per square kilometer in 2016, and the urban population density is much lower than the optimal urban population density. How to improve the population concentration level is a key issue in the current economic development.

The growth of the urban population consists of two parts: the natural growth of the internal population of the city and the migration of external population. From 2006 to 2016, the average annual growth rate of prefecture-level cities and above was $2.8 \%$, but the natural growth rate of urban population was only $4.1 \%$ to $7.5 \%$. Obviously, the current dominant factor in urban population growth is population migration. Research on population migration has a long history, and there is a large amount of literature analyzing the factors affecting population migration, regional economic differences (Zhu et al., 2001; Wang \& Chen, 2010; Liu, 2014), transportation distance (Li et al., 2004; Ma et al., 2012; Liu \& Feng, 2014) and employment are considered the main drivers of population migration. Employment is an important factor in population agglomeration. Li (2009) used the panel data of the urban-rural migration of the provincial population from 1992 to 2005 to construct an econometric model. The empirical results show that the increase in urban employment has significantly promoted the urban-rural migration. Lü \& Sun (2014), using Dongguan as an example, applied principal component analysis and multiple regression analysis to find that increasing regional jobs, increasing per capita income levels, and the path dependence of population migration can promote population agglomeration. Chen \& Sun (2016) found that employment opportunity is an important factor affecting labor mobility by constructing a theoretical model of personal selection utility function. Li \& Sun (2017) used quantile regression to find that employment in small towns in China promotes the accumulation of permanent residents, and that the number of jobs in the tertiary industry has an impact on population agglomeration more than the secondary industry.

The above literatures have studied the impact of employment opportunities on population migration and agglomeration in general. Considering that different industries have different degrees of attraction to the population, this article mainly analyzes the impact of employment in different industries on population concentration. Specifically, this article will examine the impact of employment in the secondary and tertiary industries on population agglomeration. Considering the rapid growth of new job creation in the modern service industry in recent years, the traditional service industry's ability to absorb employment has 
declined. In order to compare the difference in employment impact between traditional service industry and modern service industry employment, the service industry is subdivided into traditional and modern services. In addition, after 2012, China's economy has entered a new normal, economic growth has slowed, new jobs have been reduced, and structural reforms have increased unemployment in some industries. The transformation of economic growth power has led to changes in supply and demand in the labor market, and new changes in the employment situation, which may also change the impact of employment on population agglomeration. Therefore, this article takes the year 2012 as the boundary, and examines the impact of employment on population agglomeration in 2012 in two periods.

\section{Variables, Data and Model}

\subsection{Variables and Data}

Based on the availability of data, combined with existing research, in order to study the impact of employment on population agglomeration, this paper selects population density as the explanatory variable. It is defined as the ratio of the resident population to the area of the built-up area of the municipality (where the resident population includes the urban population and the temporary population). Take employment density, initial population density, economic development level, infrastructure level, and medical level as explanatory variables. Employment density is the ratio of employees in non-agricultural urban units in urban areas to built-up areas in urban areas. This is the most important explanatory variable in this article. A positive coefficient of the explanatory variable indicates that employment promotes population agglomeration. A larger coefficient indicates a greater impact of employment on population agglomeration. The initial population density can reflect the initial population concentration. The level of economic development is the ratio of the city's GDP to the area of the built-up area. Infrastructure level and medical level are expressed by the number of buses per unit area and the number of beds per unit area. These will generate "push" or "pull" to the population agglomeration, which will affect the changes in population density.

This article mainly divides into three industries: industry, traditional service industry and modern service industry. Industry mainly refers to the industry of raw material collection and product processing and manufacturing. This article mainly includes construction, manufacturing and other industries. The traditional service industry generally refers to industries that provide services for people's lives related to food, clothing, housing, and transportation, including wholesale and retail, transportation, warehousing and postal, accommodation and catering industries. There is no unified understanding of the concept and scope of modern service industry at present. This article quotes Jiang (2007) the concept and classification of modern service industry. Modern service industry 
mainly refers to the service industry developed by relying on high technology such as electronic information or modern business methods and organizational forms. Including financial industry, real estate industry, leasing and business service industry, information transmission and computer software industry, scientific research technology service and geological survey industry, education industry, culture, sports and entertainment industry, residential community service industry, etc. Specific variable descriptions and industry divisions are shown in Table 1.

The data in this article comes from "China Urban Construction Statistical Yearbook" and "China Urban Statistical Yearbook". The data of urban population, temporary population and built-up area are from the "China Urban Construction Statistical Yearbook", and the data of urban employment, GDP, number of buses and beds are from the "China Urban Statistical Yearbook". Because the statistical caliber of the total urban population changed in 2006, in order to ensure the consistency of the data, the initial year of this article was selected as 2006. China entered a new economic normal and the employment situation changed in 2012. Therefore, taking 2012 as the boundary, analyze the impact of employment on population agglomeration before and after the new normal of the economy. Since the data of "China Urban Construction Statistical Yearbook" was published until 2016, in view of the availability of the data, this paper selects the data from 2006-2016. Among them, the data of prefecture-level cities such as Sansha and Lhasa are relatively serious, and they are deleted. This article finally uses data from 281 prefecture-level cities and above.

\subsection{Model}

Based on the research purpose of this paper and the selection of control variables, the model settings of this paper are as follows:

Table 1. Variables and indicators.

\begin{tabular}{|c|c|c|}
\hline variable & Variable description & unit \\
\hline Population density (pden) & Permanent residents/Built-up area & people $/ \mathrm{km}^{2}$ \\
\hline Employment density (eden) & $\begin{array}{l}\text { Non-agricultural urban } \\
\text { employees/Built-up area }\end{array}$ & people $/ \mathrm{km}^{2}$ \\
\hline $\begin{array}{l}\text { Employment density in modern } \\
\text { service industries (mser) }\end{array}$ & $\begin{array}{c}\text { Modern service industry urban } \\
\text { employees/Built-up area }\end{array}$ & people $/ \mathrm{km}^{2}$ \\
\hline $\begin{array}{l}\text { Employment density in } \\
\text { traditional services (tser) }\end{array}$ & $\begin{array}{l}\text { Town employees in traditional } \\
\text { service industries/Built-up area }\end{array}$ & people $/ \mathrm{km}^{2}$ \\
\hline $\begin{array}{l}\text { Industrial employment } \\
\text { density (ind) }\end{array}$ & $\begin{array}{l}\text { Industrial town } \\
\text { employees/Built-up area }\end{array}$ & people $/ \mathrm{km}^{2}$ \\
\hline $\begin{array}{l}\text { The level of economic } \\
\text { development (gdp) }\end{array}$ & Gross domestic product/Built-up area & Ten thousand yuan $/ \mathrm{km}^{2}$ \\
\hline Infrastructure level (bus) & Bus/Built-up area & Vehicles $/ \mathrm{km}^{2}$ \\
\hline medical level (bed) & Number of beds/Built-up area & beds $/ \mathrm{km}^{2}$ \\
\hline
\end{tabular}




$$
\begin{aligned}
& \text { pden }_{i, t}=\text { cons }+\alpha_{1} \text { eden }_{i, t}+\alpha_{4} \text { pden }_{i, t-1}+\alpha_{5} \text { gdp }_{i, t-1} \\
& +\alpha_{6} \text { bus }_{i, t-1}+\beta_{7} \text { bed }_{i, t-1}+\varepsilon_{i, t} \\
& \text { pden }_{i, t}=\text { cons }+\beta_{1} \text { ind }_{i, t}+\beta_{2} \text { tser }_{i, t}+\beta_{3} \text { mser }_{i, t}+\beta_{4} \text { pden }_{i, t-1} \\
& +\beta_{5} \text { gdp }_{i, t-1}+\beta_{6} \text { bus }_{i, t-1}+\beta_{7} \text { bed }_{i, t-1}+\varepsilon_{i, t}
\end{aligned}
$$

In the above two formulas, the subscript $i$ represents the city, and $t$ represents the period. Based on the analysis above, this article divides the 2006-2016 data into three parts for empirical analysis, namely 2006-2016, 2006-2012, and 2012-2016. In the 2006-2016 model, $t$ is 2016, $t-1$ is 2006; in the 2006-2012 model, $t$ is $2012, t-1$ is 2006; in 2012-2016, $\mathrm{t}$ is $2016, t-1$ is 2012 . Equation (1) is the study of the effect of employment density on population density in general. The dependent variable is the current population density. The main explanatory variable is employment density. A positive coefficient indicates that employment opportunities have a positive effect on population concentration. Control variables include initial population density, economic development level, infrastructure level and medical level. Equation (2) analyzes the impact of employment density on population density in different industries. The biggest difference from Equation (1) is the division of employment into industrial employment, employment in traditional services, and employment in modern services.

\section{Regression Results}

China's economy has entered a new normal, and structural changes have taken place in the labor market in 2012. The impact of employment on population agglomeration may change. Therefore, based on 2012, we have made regressions from 2006 to 2016, 2006 to 2012, and 2012 to 2016. The regression results are shown in Table 2. Models 1, 3, and 5 are the regression results of overall employment density and population density, and Models 2, 4, and 6 are the regression results of employment density by population by industry.

The coefficient of employment density in Model 1 is positive and significant at the level of $1 \%$. For every increase in employment density, the population density increases by 1.038 units. This result is the same as the existing research results, indicating that the increase in employment will bring about the population concentration. The more jobs there are, the more likely people are to get employed, and the greater the employment opportunities, the more the population will gather. The main difference between Model 2 and Model 1 is that Model 2 subdivides employment density into industrial employment density, traditional service industry employment density, and modern service industry employment density. The results of Model 2 show that the impact of industrial employment density on population density is significant and positive. For every unit increase in industrial employment density, the population density increases by 0.389 units. The impact of traditional service industries on population agglomeration is not significant. The impact of modern service industry is significant. For every unit of employment density change in modern service industry, the population density changes by 2.957 units in the same direction. The effect of modern 
Table 2. Regression results.

\begin{tabular}{|c|c|c|c|c|c|c|}
\hline & Model 1 & Model 2 & Model 3 & Model 4 & Model 5 & Model 6 \\
\hline pden & \multicolumn{2}{|c|}{$2006-2016$} & \multicolumn{2}{|c|}{ 2006-2012 } & \multicolumn{2}{|c|}{$2012-2016$} \\
\hline \multirow[t]{2}{*}{ eden } & $1.038^{* * *}$ & & $1.152^{* * *}$ & & $0.498^{\star * *}$ & \\
\hline & $(0.115)$ & & $(0.119)$ & & $(0.096)$ & \\
\hline \multirow[t]{2}{*}{ ind } & & $0.389^{* *}$ & & $0.636^{* * *}$ & & 0.176 \\
\hline & & $(0.153)$ & & $(0.180)$ & & $(0.120)$ \\
\hline \multirow[t]{2}{*}{ tser } & & 0.780 & & -0.206 & & $0.939^{*}$ \\
\hline & & $(0.678)$ & & $(0.687)$ & & $(0.513)$ \\
\hline \multirow[t]{2}{*}{ mser } & & $2.957^{\star * *}$ & & $3.226^{\star * *}$ & & $1.190^{* * *}$ \\
\hline & & $(0.432)$ & & $(0.434)$ & & $(0.351)$ \\
\hline \multirow[t]{2}{*}{ L.pden } & $0.205^{\star * *}$ & $0.198^{\star * *}$ & $0.369^{* * *}$ & $0.362^{\star * *}$ & $0.644^{\star * *}$ & $0.618^{* * *}$ \\
\hline & $(0.033)$ & $(0.032)$ & $(0.033)$ & $(0.032)$ & $(0.038)$ & $(0.039)$ \\
\hline \multirow[t]{2}{*}{ L.gdp } & $-0.027^{\star \star \star}$ & $-0.018^{\star * *}$ & $-0.027^{\star * *}$ & $-0.020^{\star * *}$ & $-0.006^{* *}$ & -0.004 \\
\hline & $(0.005)$ & $(0.005)$ & $(0.005)$ & $(0.005)$ & $(0.002)$ & $(0.002)$ \\
\hline \multirow[t]{2}{*}{ L.bus } & $48.80^{* * *}$ & $46.78^{\star * *}$ & $39.05^{\star * *}$ & $41.365^{\star * *}$ & $20.96^{\star * *}$ & $20.44^{* * *}$ \\
\hline & $(7.776)$ & $(7.460)$ & $(7.740)$ & $(7.617)$ & $(6.302)$ & (6.218) \\
\hline \multirow[t]{2}{*}{ L.bed } & $12.99^{\star * *}$ & $7.992^{\star *}$ & $7.032^{\star}$ & 3.016 & 0.893 & -0.398 \\
\hline & $(3.807)$ & (3.755) & $(3.836)$ & (3.901) & $(2.850)$ & $(2.849)$ \\
\hline \multirow[t]{2}{*}{ _cons } & $4240.85^{\star * *}$ & $3841.16^{* * *}$ & $3443.19^{* * *}$ & $3211.60^{* * *}$ & $1670.41^{* * *}$ & $1538.24^{\star * *}$ \\
\hline & (381.91) & $(362.92)$ & $(377.91)$ & $(376.84)$ & $(290.54)$ & $(267.29)$ \\
\hline $\mathrm{N}$ & 281 & 281 & 281 & 281 & 281 & 281 \\
\hline $\mathrm{R} 2$ & 0.53 & 0.58 & 0.61 & 0.63 & 0.75 & 0.76 \\
\hline
\end{tabular}

$t$ statistics in parentheses; ${ }^{*} p<0.10,{ }^{* *} p<0.05,{ }^{* * *} p<0.01$.

service industry on population concentration far exceeds that of industry. The service industry itself has a strong ability to absorb employment, among which the employment growth rate of modern service industry is faster. The fastest growing employment in the service industry from 2006 to 2016 was information transmission and computer software, real estate, finance, and leasing and business services, which increased by $190.7 \%, 162.52 \%, 111 \%$, and $105.18 \%$ respectively. The modern service industry has the fastest employment growth, with more new jobs and greater employment opportunities, and the more obvious the role of promoting population concentration.

From different time periods, the influence of employment opportunities on the population agglomeration gradually decreases over time. The coefficients of changes in employment density in Models 3 and 5 are both significantly positive, with coefficients of 1.152 and 0.498 , respectively. The decrease of the coefficients indicates that the impact of employment opportunities on population agglomeration is decreasing. This is closely related to the stage of economic develop- 
ment. From 2006 to 2012, China's economy was in a period of accelerated economic development. The actual GDP growth rate was basically above $10 \%$. During the period of rapid economic development, cities have a large number of jobs and require a large number of working population, so population concentration is rising rapidly. From 2012 to 2016, the actual growth rate of GDP dropped from $7.9 \%$ to $6.7 \%$, and the development rate slowed down. The employment of cities tended to be saturated, and the attractiveness of employment to the population concentration decreased. In addition, the rising cost of living in prefecture-level cities and above, the emergence of urban problems, changes in people's living concepts, and the declining surplus rural labor force will all lead to a decline in the attractiveness of employment opportunities to the population concentration of prefecture-level cities and above. From the perspective of specific industries, after China's entry into the new economic normal, the impact of employment in industry, traditional services, and modern services on population agglomeration has also changed. Industrial employment has a significant impact on population agglomeration from 2006 to 2012. A change of one unit in the industrial employment density will cause 0.636 units of population density to change in the same direction. After 2012, the effect of industrial employment on population agglomeration is no longer significant. For every unit of employment density change in the modern service industry before and after 2012, the population density changes by 3.226 units and 1.190 units in the same direction, indicating that the role of employment in the modern service industry on population concentration has declined. Employment in the traditional service industry has changed from insignificant to significant, but it is only significant at a significance level of $10 \%$. Therefore, the impact of employment in the traditional service industry on population agglomeration has not changed significantly.

From the perspective of other control variables, most of the control variables have significant effects on population agglomeration. The coefficient of the initial population density is positive. Cities with higher initial population density now have higher population densities, which is consistent with China's rising urbanization level. The level of economic development has a negative impact on population density, and the population concentration in areas with more developed economies is slower. The more developed the economy, the more prone to urban problems such as energy shortages, traffic congestion, and environmental pollution, resulting in a decline in the quality of life of residents and an increase in the cost of living, which hinders the population agglomeration to a certain extent. The impact of transportation and medical treatment on population density changes is positive. The level of infrastructure and medical treatment will pull the population concentration. With the steady development of the economy, people are paying more and more attention to the level of public services such as transportation, medical treatment and education in cities.

\section{Conclusion}

This article uses prefecture-level city data to study the relationship between em- 
ployment density and population density from 2006 to 2016, 2006 to 2012, and 2012 to 2016, respectively. First, the impact of employment on population agglomeration is examined on the whole, and then the analysis of industry, traditional services, and modern services is conducted. Second, it analyzes the impact of employment on population agglomeration around 2012. The following conclusions are obtained: 1) From 2006 to 2016, employment positively significantly affected the level of population agglomeration, employment of industrial and modern service industries had a significant impact, and employment of traditional service industries had no significant impact on population agglomeration. 2) From different time periods, the impact of employment density on population agglomeration is gradually decreasing. After 2012, the impact of industrial employment density on population agglomeration has changed from significant to insignificant. Although the employment impact of modern service industry is still significant, its influence on the impact of employment in traditional services has not changed significantly. 3) The impact of initial population density, infrastructure level and medical level on population agglomeration is significantly positive, and the level of economic development has a negative impact on population agglomeration. Based on the above conclusions, local governments can promote population agglomeration through the following measures.

Firstly, the government should rationally layout the industrial structure. The rational planning of the industrial structure is not only conducive to the development of the local economy, but also can increase employment and promote population concentration. Large cities should actively develop modern service industries that have a greater impact on population agglomeration capabilities and improve population absorption capacity. Small and medium cities should develop their own advantageous industries based on their endowment and use them to drive the development of other related industries and infrastructure. Effectively drive population concentration.

Secondly, persist in leading the urban population gathering with talent gathering. Under the new normal economy, China's economic growth momentum has changed, from the original factor-driven and investment-driven to innovation-driven. The development of innovative industries is inseparable from talents, and the concentration of urban population is the concentration of talents. Cities should formulate plans for the introduction of skilled and knowledgeable talents based on the industry's demand for talents, so as to balance supply and demand in the labor market.

Finally, improve public services. Strengthen the construction of urban road transportation infrastructure, actively develop ground public transportation, and improve transportation systems such as subways and light rails; strengthen urban primary medical care construction, strengthen primary health personnel, and improve the level of primary medical services. Only by vigorously strengthening infrastructure construction, improving public standards such as transportation and medical care, and improving the quality of life of residents, can population concentration be enhanced. 


\section{Conflicts of Interest}

The author declares no conflicts of interest regarding the publication of this paper.

\section{References}

Chen, H., \& Sun, B. D. (2016). Wage Level, Employment Opportunity and Population Mobility: An Empirical Analysis Based on Quantile Regression. Industrial Economic Review, No. 5, 105-115.

Jiang, S. G. (2007). Research on Modern Service Industry. Beijing: China Economic Press.

Li, F. J., \& Sun, Y. (2017). Employment Scale Effect of Industrial Transfer in China: Theory and Empirical. Labor Economic Review, 10, 125-139.

Li, G. P., Xuan, Z. H., \& Wang, L. M. (2004). Measurement and Analysis of Regional Economic Links between Shenzhen and the Country-A Study Based on Population Migration Model. Human Geography, No. 2, 30-34.

Li, P. (2009). Temporal and Spatial Characteristics of Urban and Rural Population Migration and Its Influencing Factors in China. Economist, No. 1, 50-57.

Liu, S. L. (2014). Analysis of the Influencing Factors of Population Migration across Provinces in China. Quantitative Economics, Technical Economics Research, 31, 83-98.

Liu, Y. L., \& Feng, J. (2014). Characteristics of Population Migration in China and Its Influencing Factors: Analysis Based on the Data of the Sixth Census. Human Geography, 29, 129-137.

Lü, C., \& Sun, W. (2014). Influencing Factors of Population Migration in the Agglomeration Areas-Taking Dongguan as an Example. Progress in Geography, No. 5, 593-604.

Ma, W., Wang, Y. H., \& Liu, S. L. (2012). Transportation Infrastructure and Population Migration in China: Analysis Based on Gravity Model. China Soft Science, No. 3, 69-77.

Su, H. J., \& Wei, H. K. (2013). Density Effect, Optimal Urban Population Density and Intensive Urbanization. China Industrial Economy, 10, 5-17.

Wang, H. N., \& Chen, Y. Y. (2010). A Comparative Analysis of the Influencing Factors of Migrants in Beijing, Tianjin and Shanghai. Population and Development, 16, 21-28.

Zhu, C. G., Gu, C. L., Ma, R. H., Zhen, F., \& Zhang, W. (2001). Influencing Factors and Spatial Distribution of Floating Population in China. Journal of Geographical Sciences, No. 5, 548-559. 